\title{
Effect of pruning intensity on soil moisture and water use efficiency in jujube (Ziziphus jujube Mill.) plantations in the hilly Loess Plateau Region, China
}

\author{
JIN Shanshan ${ }^{1}$, WANG Youke ${ }^{1,2 *}$, WANG Xing ${ }^{2}$, BAI Yonghong ${ }^{3}$, SHI Leigang ${ }^{4}$ \\ ${ }^{1}$ College of Water Resources and Architectural Engineering, Northwest A\&F University, Yangling 712100, China; \\ ${ }^{2}$ Research Center of Soil and Water Conservation and Ecological Environment, Chinese Academy of Sciences \& Ministry of \\ Education, Yangling 712100, China; \\ ${ }^{3}$ College of Natural Resources and Environment, Northwest A\&F University, Yangling 712100, China; \\ ${ }^{4}$ Beijing Research Center of Information Technology in Agriculture, Beijing 100097, China
}

\begin{abstract}
Jujube (Ziriphus jujube Mill.) is a traditional economic forest crop and is widely cultivated in hilly areas of the Loess Plateau, China. However, soil desiccation was discovered in jujube plantations. Pruning is recognized as a water-saving method that can reduces soil water consumption. In this study, we monitored the jujube plots with control $(\mathrm{CK})$, light $\left(\mathrm{C}_{1}\right)$, medium $\left(\mathrm{C}_{2}\right)$ and high $\left(\mathrm{C}_{3}\right)$ pruning intensities during the jujube growing period of 2012-2015 to explore the effect of pruning intensity on soil moisture and water use efficiency (WUE) of jujube plantations in the hilly Loess Plateau Region. The results showed that pruning is an effective method for soil water conservation in jujube plantations. Soil moisture increased with increasing pruning intensity during the jujube growing period of $2012-2015 . C_{1}, C_{2}$ and $C_{3}$ pruning intensities increased soil water storage by $6.1-18.3,14.4-40.0$ and $24.3-63.3 \mathrm{~mm}$, respectively, compared to $\mathrm{CK}$ pruning intensity. Pruning promoted soil moisture infiltration to deeper soil layer. Soil moisture infiltrated to soil depths of 240,280 and $>300 \mathrm{~cm}$ under $C_{3}$ pruning intensity, 220, 260 and 260 $\mathrm{cm}$ under $\mathrm{C}_{2}$ pruning intensity, 200, 240 and $220 \mathrm{~cm}$ under $\mathrm{C}_{1}$ pruning intensity, and 180, 200 and $160 \mathrm{~cm}$ under CK pruning intensity in 2013, 2014 and 2015, respectively. Soil water deficit was alleviated by higher pruning intensity. In 2013-2015, soil water change was positive under $C_{2}(6.4 \mathrm{~mm})$ and $C_{3}(26.8 \mathrm{~mm})$ pruning intensities but negative under $C_{1}(-20.5 \mathrm{~mm})$ and $\mathrm{CK}(-40.6 \mathrm{~mm})$ pruning intensities. Moreover, pruning significantly improved fresh fruit yield and WUE of jujube plants. Fresh fruit yields were highest under $C_{1}$ pruning intensity with the values of $6897.1-13,059.3 \mathrm{~kg} / \mathrm{hm}^{2}$, which were $2758.4-4712.8$, $385.7-1432.1$ and $802.8-2331.5 \mathrm{~kg} / \mathrm{hm}^{2}$ higher than those under $\mathrm{CK}, \mathrm{C}_{2}$, and $\mathrm{C}_{3}$ pruning intensities during the jujube growing period of 2012-2015, respectively. However, $C_{3}$ pruning intensity had the highest WUE values of $2.92-3.13 \mathrm{~kg} / \mathrm{m}^{3}$, which were $1.6-2.0,1.1-1.2$ and $1.0-1.1$ times greater than those under $\mathrm{CK}, \mathrm{C}_{1}$ and $\mathrm{C}_{2}$ pruning intensities, respectively. Therefore, $\mathrm{C}_{3}$ pruning intensity is recommended to jujube plantations for its economic and ecological benefits. These results provide an alternative strategy to mitigate soil desiccation in jujube plantations in the hilly Loess Plateau Region, which is critical for sustainable cultivation of economic forest trees in this region.
\end{abstract}

Keywords: pruning intensity; soil desiccation; yield; water use efficiency; Zįiphus jujube Mill.; Loess Plateau

Citation: JIN Shanshan, WANG Youke, WANG Xing, BAI Yonghong, SHI Leigang. 2019. Effect of pruning intensity on soil moisture and water use efficiency in jujube (Ziziphus jujube Mill.) plantations in the hilly Loess Plateau Region, China. Journal of Arid Land, 11(3): 446-460. https://doi.org/10.1007/s40333-019-0129-z

*Corresponding author: WANG Youke (E-mail: gjzwyk@vip.sina.com)

Received 2018-05-24; revised 2018-07-27; accepted 2018-10-10

(C) Xinjiang Institute of Ecology and Geography, Chinese Academy of Sciences, Science Press and Springer-Verlag GmbH Germany, part of Springer Nature 2019 


\section{Introduction}

The inappropriate selection of forest species and overemphasis on tree and shrub planting in vegetation construction and environmental restoration have caused soil desiccation and widespread dried soil layer in artificial forests and grasslands in the hilly Loess Plateau Region of China (Li, 1983; Shangguan, 2007; Chen et al., 2008; Fu et al., 2012; Jia et al., 2017; Gao et al., 2018). In arid and semi-arid areas, excessive depletion of deep soil moisture due to inappropriate vegetation types and long-term drought has made ecological restoration through land use change be difficult (Chen et al., 2008). Soil desiccation also occurs in many other areas of the world, such as Russia, eastern Amazonia and Brazil, where the amount of annual rainfall is lower than that of annual water use (Yang and Han, 1985; Jipp et al., 1998; Oliveira et al., 2005; Robinson et al., 2006).

Jujube (Ziziphus jujube Mill.) is an important traditional economic forest species in the hilly Loess Plateau Region, China. Its cultivated area exceeds $6.67 \times 10^{4} \mathrm{hm}^{2}$ as a major agroforestry industry in this region. However, dried soil layer is found in jujube plantations due to high planting intensity and extensive and low-level management model. The depth of dried soil layer in a twelve-year-old jujube plantation can reach up to $540 \mathrm{~cm}$ (Wang et al., 2015) and there almost has no available water in the $200-400 \mathrm{~cm}$ soil layer in a nine-year-old jujube plantation (Liu et al., 2014). This suggests that the degree of soil water deficit is worsened over time in jujube plantations (Xin et al., 2012). And if the current planting pattern continues, the hydrological and ecological environment will eventually be irreparably damaged.

Many studies have been conducted to determine the formation and characteristics of soil desiccation or dried soil layer in cultivated lands (Wang and Shao, 2004; Chen et al., 2005; Shao et al., 2016). Researchers have also proposed some measures, such as crop rotation, mulching and appropriate mixed tree/shrub planting, to alleviate soil water depletion especially in arid and semi-arid regions (Wang et al., 2008; Fang et al., 2010; Wang et al., 2012; Fan et al., 2014; Gao et al., 2018).

Pruning is a common agronomic method used to increase crop yield and fruit quality (Martin et al., 1980; Max et al., 2016), because it can change vegetation structure, improve light energy utilization (Yang et al., 1998; Forrester et al., 2012) and increase fruit setting rate and soluble sugar content (Pei et al., 2013). Recently, pruning is recognized as a water-saving method that can reduce soil water consumption (Shelden and Sinclair, 2000; López et al., 2008; Alcorn et al., 2013). Jackson et al. (2000) reported that tree pruning has been used as a part of agroforestry management practices to control water use. Pruning narrows the xylem vessels in Senna spectabilis and reduces the rate of transpiration and water consumption (Namirembe et al., 2009). It reduces the dipping diameter of jujube plant, which in turn increases the soil water storage (Chen et al., 2016). Wei et al. (2014) found a decline in the rate of sap flow in pruned jujube plants, compared with non-pruned plants, especially during the flowering and fruit enlargement periods. Moreover, wedge shapes are observed to form in dead tissues at the cut surfaces of pruned grapes, which affect the properties of catheter and sieve tubes and cause a significant decline in the sap flow rate (Zhao, 2013). Many studies showed that pruning is an effective method for ensuring the normal growth of jujube under drought or water deficit conditions (Chen et al., 2016; Wang et al., 2017; Zhang et al., 2017).

Studies of pruning were mainly focused on a short timescale, and there was little research on the effect of pruning on interannual variation of soil water conditions, especially in fragile ecological environments. Moreover, there were few well-structured scientific experiments or quantitative analyses concerning pruning intensity and its effect on crop yield and water use efficiency (WUE). In this study, the effects of pruning intensity on the spatiotemporal variation of soil moisture and on the tree growth characteristics of jujube plants were determined under natural rainfall conditions in the hilly Loess Plateau Region. The aims of the study were to evaluate the effects of pruning intensity on soil moisture, yield and WUE of jujube plantations, and to find a suitable pruning intensity for soil water conservation, recovery of dried soil layer and soil sustainable productivity. It is our hope that this study could provide scientific reference to 
prevent environmental degradation in the hilly Loess Plateau Region and to promote the sustainable cultivation of jujube economic forests in hilly regions.

\section{Materials and methods}

\subsection{Study area}

The field experiment was conducted at Mizhi Experimental Station, Northwest A\&F University, Shaanxi Province, Northwest China $\left(37^{\circ} 25^{\prime} \mathrm{N}, 108^{\circ} 49^{\prime} \mathrm{E} ; 892 \mathrm{~m}\right.$ a.s.l.). The study area locates in the hinterland of the Loess Plateau with hills and gullies on a slope of $8^{\circ}-12^{\circ}$ and with severe soil erosion. It is characterized by a typical semi-arid temperate climate with annual mean temperature of $8.5^{\circ} \mathrm{C}$, latent evaporation of $1650.0 \mathrm{~mm}$, total radiation of $582.7 \mathrm{~kJ} / \mathrm{cm}^{2}$, total sunshine duration of $2761 \mathrm{~h}$ and mean annual rainfall of $451.6 \mathrm{~mm}$, which mainly falls from July to September. We classified the years 2012, 2013 and 2014 as "wet years" with annual rainfall of $608.3 \mathrm{~mm}, 529.8$ $\mathrm{mm}$ and $526.0 \mathrm{~mm}$, respectively, and the year 2015 as "dry year" with annual rainfall of 359.4 $\mathrm{mm}$ based on the fifty years of meteorological data and the classification standards of hydrological years (Zhang et al., 2008).

The soil is uniform in texture in the $0-300 \mathrm{~cm}$ soil layer, with silt, sand and clay fractions of $7.7 \%, 47.8 \%$ and $44.5 \%$, respectively. Mean bulk density of the soil is $1.31 \mathrm{~g} / \mathrm{cm}^{3}$ in the upper $300 \mathrm{~cm}$ soil layer. The soil field capacity by mass is $22.0 \%$, with a wilting point of $5.5 \%$. The water table is $>50 \mathrm{~m}$ below ground.

\subsection{Experimental design}

Four similar horizontal terraces were selected on the southern slope (about $5^{\circ}$ ), where dwarf and densely jujube trees were cultivated in 2000 and regularly pruned in each year. Each horizontal terrace was treated as a separate plot and each plot was approximately $1.0 \mathrm{hm}^{2}$. The plant spacing was $3 \mathrm{~m} \times 2 \mathrm{~m}$, with a density of $1666 \mathrm{plants} / \mathrm{hm}^{2}$ in jujube plantations. We set four treatments for the jujube plant. They were control $(\mathrm{CK})$, light $\left(\mathrm{C}_{1}\right)$, medium $\left(\mathrm{C}_{2}\right)$ and high $\left(\mathrm{C}_{3}\right)$ pruning intensities during the jujube growing periods of 2012-2015 (Fig. 1; Table 1). CK was the regular and the lowest pruning intensity. Plants were pruned as the standards described in Table 1. Pruning checks were conducted every seven days. Approximately six jujube plants were randomly selected as replicates for each treatment.

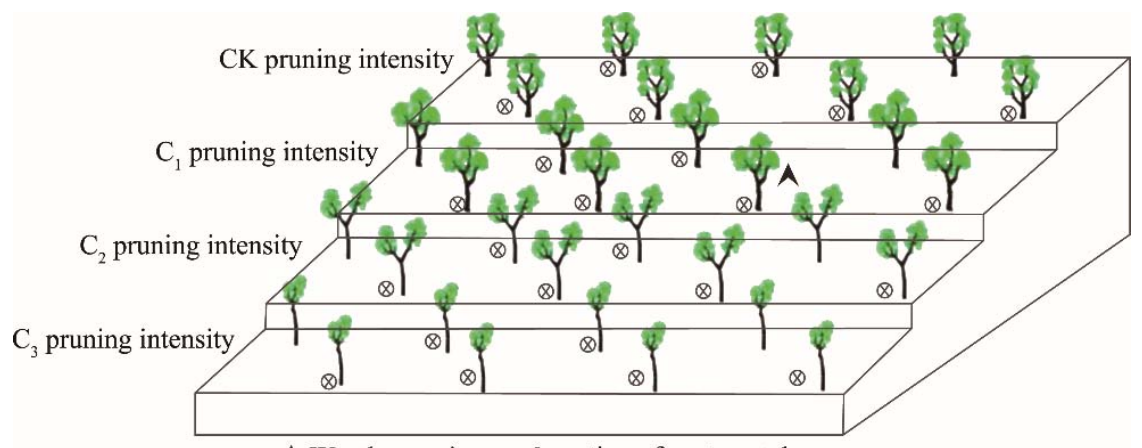

A Weather station $\otimes$ Location of neutron tube

Fig. 1 Layouts of the experimental plots and the jujube plants under four pruning intensities at Mizhi Experimental Station in the hilly Loess Plateau Region. $\mathrm{CK}$, control; $\mathrm{C}_{1}$, light; $\mathrm{C}_{2}$, medium; $\mathrm{C}_{3}$, high.

Table 1 Standards of jujube plants under four pruning intensities

\begin{tabular}{cccc}
\hline Pruning intensity & Plant height after pruning $(\mathrm{cm})$ & $\begin{array}{c}\text { Number of } \\
\text { leading shoots remaining }\end{array}$ & $\begin{array}{c}\text { Total length of } \\
\text { lateral branch remaining }(\mathrm{cm})\end{array}$ \\
\hline $\mathrm{CK}$ & 220 & 4 & $575-625$ \\
$\mathrm{C}_{1}$ & 200 & 3 & $425-475$ \\
$\mathrm{C}_{2}$ & 180 & 2 & $275-325$ \\
$\mathrm{C}_{3}$ & 160 & 1 & $125-175$ \\
\hline
\end{tabular}


Only robust branches were selected as leading shoots. Thin and diseased branches were also pruned, but no branch was left below leading shoots. Dislocation was used to prune leading shoots and lateral branches to avoid the mutual occlusion among the branches and ensure sufficient access to sunlight. Pruned leading shoots were hardly changed in the following year, so pruning was mainly used to control the length of lateral branches.

Around each experimental plant, a $100 \mathrm{~cm}$ deep ditch was excavated and then covered with thick plastic around the inner ditch walls to avoid soil moisture from the surrounding area influencing the experimental plot. Loess soil in this area was loose and had good infiltration capacity, so it was well-drained and had no runoff or deep percolation under low rainfall intensity conditions (light rainy days with rainfall of $<10 \mathrm{~mm} / \mathrm{d}$ account for $90 \%-97 \%$ of the total number of rainy days). Therefore, the natural environmental condition of the four terraces were similar. No fertilizer or irrigation was applied during the experimental period.

\subsection{Data acquisition}

\subsubsection{Soil moisture}

A neutron moisture gauge (CNC503B, Super Energy Nuclear Technology Limited, Beijing, China) was used to monitor soil water content to a depth of $300 \mathrm{~cm}$ for each treatment. A neutron tube was mounted $50 \mathrm{~cm}$ to the west side of the jujube plant roots and monitoring was conducted every $15 \mathrm{~d}$ at soil depth intervals of $20 \mathrm{~cm}$. We corrected the neutron probes every three months and then calculate the soil water content based on a correction equation. Considering the inaccuracy of neutron method in measuring surface soil water content, we used oven-drying method to determine the soil water content in the $0-20 \mathrm{~cm}$ soil layer.

\subsubsection{Meteorological parameters}

A small meteorological instrument (BJJW-4, Beijing Yungen Technology Company Limited, Beijing, China) was installed at the experimental station. The meteorological parameters monitored were sunshine duration $(S H ; \mathrm{h})$, air temperature $\left(T ;{ }^{\circ} \mathrm{C}\right)$, rainfall $(P ; \mathrm{mm})$, soil heat flux $\left(G ; \mathrm{W} / \mathrm{m}^{2}\right)$, relative humidity $(R H ; \%)$, solar radiation $\left(R ; \mathrm{W} / \mathrm{m}^{2}\right)$, wind speed $(u ; \mathrm{m} / \mathrm{s})$ and solar net radiation $\left(R_{\mathrm{n}} ; \mathrm{W} / \mathrm{m}^{2}\right)$. Meteorological data were recorded every $30 \mathrm{~min}$.

\subsubsection{Growth indicators of Jujube}

The growth indicators included: leading shoots (number), lateral branches (number, length and diameter), shed shoots (number, length and diameter; ten shed shoots were selected from east, west, north and south directions, respectively), fruits and leaves (number, transverse and longitudinal diameter; ten fruits or leaves were selected from east, west, north and south directions, respectively), weight of single fresh fruit at the fruit ripenning stage (30 fruits were randomly selected and their average weight was calculated) and yield (total weight; all fruits of the plants in each treatment). Lengths were measured using a tape $(\mathrm{cm})$ and diameters were measured using a vernier caliper $(\mathrm{mm})$. These measurements were taken every seven days from May to October in each year.

\subsection{Statistical analyses}

\subsubsection{Soil water storage}

$$
\mathrm{SWS}_{0-300 \mathrm{~cm}}=\sum_{i=1}^{n}\left(\theta_{i} \times h_{i}\right)
$$

where $\mathrm{SWS}_{0-300 \mathrm{~cm}}$ is the soil water storage in the $0-300 \mathrm{~cm}$ soil layer $(\mathrm{mm}) ; \theta_{i}$ is the soil volumetric water content in the $i^{\text {th }}$ soil layer $\left(\mathrm{cm}^{3} / \mathrm{cm}^{3}\right)$; and $h_{i}$ is the soil thickness in the $i^{\text {th }}$ soil layer ( $\mathrm{mm} ; h_{i}=200 \mathrm{~mm}$ in any soil layer in this study).

2.4.2 Coefficient of variation $(\mathrm{CV})$

$$
\mathrm{CV}=\frac{S}{\bar{X}} \times 100 \%
$$

where $\mathrm{CV}$ is the coefficient of variation (\%); $S$ is the standard deviation; and $\bar{X}$ is the average 
value. CV reflects the degree of discretization of the random variables. $C V \geq 100 \%$ indicates strong variability of the random variables, $10 \% \leq \mathrm{CV}<100 \%$ indicates medium variability of the random variables and $\mathrm{CV}<10 \%$ indicates weak variability of the random variables (Zhang et al., 2016).

2.4.3 Water balance equations

The water balance equations for forests are as follows:

$$
\begin{gathered}
\Delta S=(P+I)-(C+E T+O+D), \\
\Delta S=S_{\text {initial }}-S_{\text {present }},
\end{gathered}
$$

where $\Delta S$ is the change in soil water storage in the $0-300 \mathrm{~cm}$ soil layer $(\mathrm{mm}) ; P$ is the rainfall $(\mathrm{mm}) ; I$ is the irrigation amount $(\mathrm{mm}) ; C, E T, O$ and $D$ are the canopy interception, evapotranspiration, surface runoff and deep percolation $(\mathrm{mm})$, respectively, and they are the depletive variables of soil moisture; $S_{\text {initial }}$ is the initial soil water storage (mm); and $S_{\text {present }}$ is the present soil water storage $(\mathrm{mm})$.

In this study, canopy interception was not considered because pruned jujube trees had small crowns and rainfall intensity was limited in the study area. Deep percolation was ignored because ground water table was $>50 \mathrm{~m}$ and the tested plot was horizontal and had an angle of inclination toward the mountain interior. Surface runoff was excluded because the soil in the study area had strong hydraulic conductivity. No irrigation was applied during the study period. Therefore, Equation could be rewritten as:

$$
E T=P-\Delta S .
$$

\subsubsection{Index of soil desiccation}

We used the degree of soil water deficit to obtain a more accurate and quantitative description of the intensity of soil desiccation according to the following formula (Yi et al., 2009):

$$
K=\left(\theta_{a}-\theta\right) / \theta_{a} \times 100 \%,
$$

where $K$ is the soil desiccation index, which represents the degree of soil water deficit (dimensionless); $\theta_{a}$ is the stable field capacity $\left(\mathrm{cm}^{3} / \mathrm{cm}^{3}\right)$, accounting for $60 \%$ of the field capacity $\left(13.2 \%\right.$ in this study); and $\theta$ is the soil volumetric water content $\left(\mathrm{cm}^{3} / \mathrm{cm}^{3}\right)$. According to the study of Li (1983), the stable field capacity represents the original soil moisture regime below the typical layer $(200 \mathrm{~cm})$ of infiltration from surface water, without the influence of soil evaporation and root water uptake. We divided the intensity of soil desiccation into four grades based on the $K$ values: serious water deficit, when $K$ value is $>50 \%$; moderate water deficit, when $K$ value is $25 \%-50 \%$; minor water deficit, when $K$ value is $0-25 \%$; and no deficit, when $K$ value is $<0$.

\subsubsection{Biomass of jujube}

The biomass of each growth part of jujube is calculated as follows (She et al., 2015):

$$
\begin{gathered}
B_{\mathrm{b}}=0.002 D_{\mathrm{b}}^{1.564} L_{\mathrm{b}}^{1.016}, \\
B_{\mathrm{s}}=0.005 D_{\mathrm{s}}^{1.02} L_{\mathrm{s}}^{1.078}, \\
B_{\mathrm{l}}=T_{1}^{0.901} V_{1}^{1.374} \times 4.568 \times 10^{-5}, \\
B_{\mathrm{f}}=0.631 T_{\mathrm{f}}^{3.6011 \times 10^{-8}} V_{\mathrm{f}}^{0.999},
\end{gathered}
$$

where $B_{\mathrm{b},} B_{\mathrm{s}}, B_{1}$ and $B_{\mathrm{f}}$ are the biomasses (fresh weight) of new branches, shed shoots, leaves and fruits $(\mathrm{g})$, respectively; $D_{\mathrm{b}}$ and $D_{\mathrm{s}}$ are the diameters of new branches and shed shoots $(\mathrm{mm})$, respectively; $L_{\mathrm{b}}$ and $L_{\mathrm{s}}$ are the lengths of new branches and shed shoots $(\mathrm{mm})$, respectively; $T_{1}$ and $T_{\mathrm{f}}$ are the transverse diameters of new leaves and fruits $(\mathrm{mm})$, respectively; and $V_{1}$ and $V_{\mathrm{f}}$ are the longitudinal diameters of new leaves and fruits $(\mathrm{mm})$, respectively.

\subsubsection{Water use efficiency (WUE)}

WUE of different treatments was calculated using the following equation (Hussain and Al-Jaloud, 
1998):

$$
\mathrm{WUE}=Y / E T,
$$

where WUE is the water use efficiency $\left(\mathrm{kg} / \mathrm{m}^{3}\right) ; Y$ is the fresh fruit yield $\left(\mathrm{kg} / \mathrm{hm}{ }^{2}\right)$; and $E T$ is the evapotranspiration, as defined in Equation 5.

\subsubsection{Statistical methods}

All statistical analysis was performed using Microsoft Excel 2010 (Microsoft Inc., Redmond, Washington, USA) and SPSS 16.0 (SPSS Inc., Chicago, IL, USA). The significant difference analysis was performed by one-way ANOVA.

\section{Results}

\subsection{Temporal variation of soil water storage}

Total rainfall during the jujube growing period (from May to October) was $419.2 \mathrm{~mm}$ in 2012, $492.2 \mathrm{~mm}$ in 2013, $413.8 \mathrm{~mm}$ in 2014 and $250.4 \mathrm{~mm}$ in 2015 (Fig. 2), accounting for 69\%, 94\%, $79 \%$ and $70 \%$ of the annual rainfall, respectively. These results suggested a great variation of rainfall during the four years.

Correspondingly, significant fluctuations in soil water storage were observed during the jujube growing period of 2012-2015 (Fig. 2). In May 2012, initial soil water storage was in the order of $\mathrm{C}_{2}>\mathrm{CK}>\mathrm{C}_{1}>\mathrm{C}_{3}$ pruning intensity, but this order was $\mathrm{C}_{3}>\mathrm{C}_{2}>\mathrm{C}_{1}>\mathrm{CK}$ after July 2012 due to soil moisture infiltration, transport and redistribution. Compared with $\mathrm{CK}$ pruning intensity, soil water storage in 2012-2015 improved by $6.1-18.3,14.4-40.0$ and $24.3-63.3 \mathrm{~mm}$ under $\mathrm{C}_{1}, \mathrm{C}_{2}$ and $\mathrm{C}_{3}$ pruning intensities, respectively.
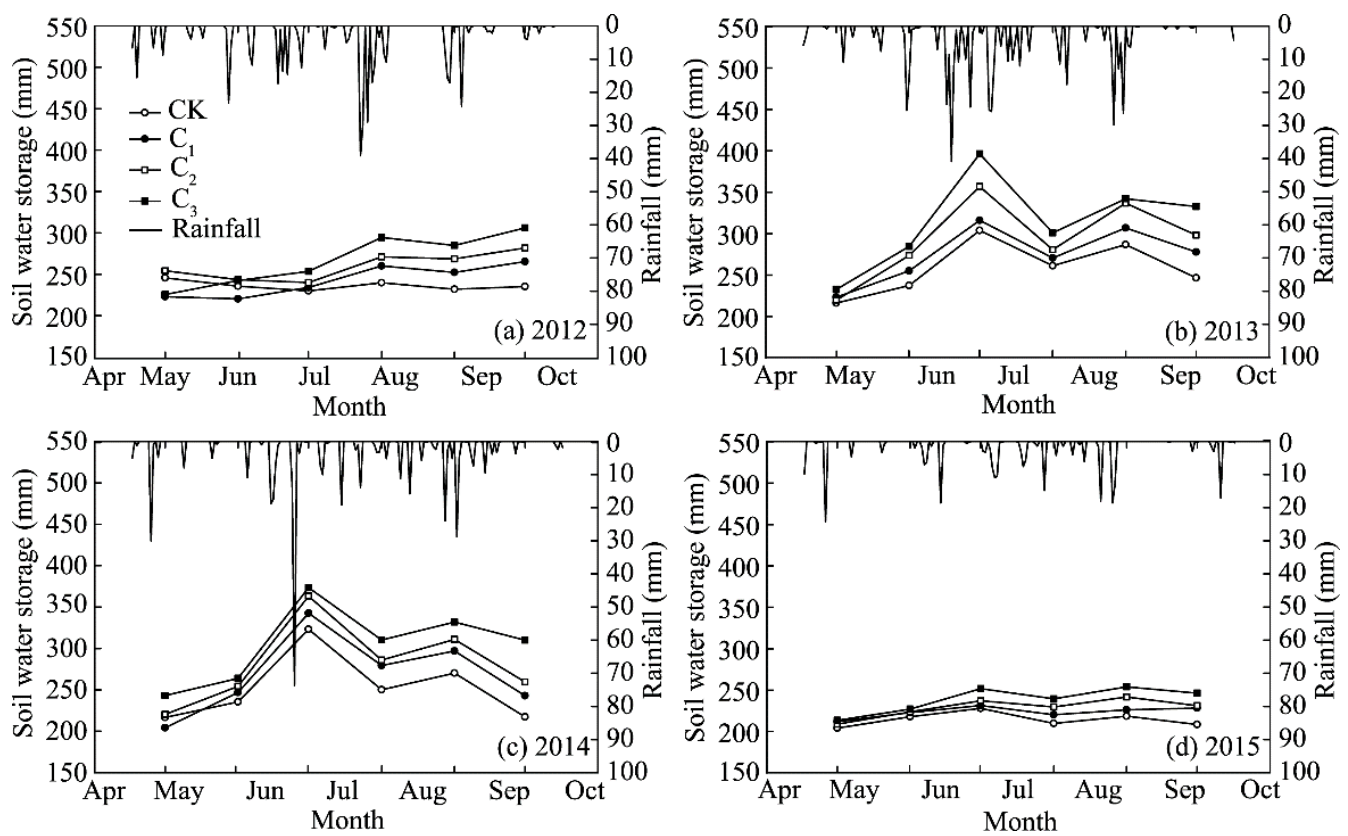

Fig. 2 Variation dynamics of average monthly soil water storage and rainfall in the 0-300 cm soil layer under four pruning intensities (CK, control; $\mathrm{C}_{1}$, light; $\mathrm{C}_{2}$, medium; $\mathrm{C}_{3}$, high) of jujube plantations in (a) 2012, (b) 2013 , (c) 2014 and (d) 2015

Table 2 lists the average soil water storage during the jujube growing period of 2012-2015 under four pruning intensities. The average soil water storage was highest in 2013 (a high rainfall year) and lowest in 2015 (a low rainfall year) under all pruning intensities. Although there was a similar amount of rainfall in 2012 and 2014, the differences in the average soil water storage among the four pruning intensities were larger in 2014 than in 2012. This result may be attributed to the influence of more rainfall in 2013. 
Table 2 Average soil water storage of jujube plantations under four pruning intensities during the jujube growing period of 2012-2015

\begin{tabular}{cllll}
\hline \multirow{2}{*}{ Pruning intensity } & \multicolumn{4}{c}{ Soil water storage $(\mathrm{mm})$} \\
\cline { 2 - 5 } & 2012 & 2013 & 2014 & 2015 \\
\hline CK & $236.4^{\mathrm{c}}$ & $271.6^{\mathrm{c}}$ & $252.2^{\mathrm{c}}$ & $214.1^{\mathrm{bc}}$ \\
$\mathrm{C}_{1}$ & $242.6^{\mathrm{bc}}$ & $289.8^{\mathrm{bc}}$ & $268.7^{\mathrm{b}}$ & $223.2^{\mathrm{b}}$ \\
$\mathrm{C}_{2}$ & $260.4^{\mathrm{b}}$ & $311.6^{\mathrm{b}}$ & $284.0^{\mathrm{b}}$ & $228.4^{\mathrm{ab}}$ \\
$\mathrm{C}_{3}$ & $267.8^{\mathrm{a}}$ & $334.8^{\mathrm{a}}$ & $305.4^{\mathrm{a}}$ & $238.3^{\mathrm{a}}$ \\
\hline
\end{tabular}

Note: Different lowercase letters within the same column represent significant differences of soil water storage under four pruning intensities for the same year at $P<0.05$ level.

\subsection{Vertical distributions of soil moisture}

The depths of soil moisture infiltration during the growing period of 2012-2015 under four pruning intensities of jujube plantations are shown in Figure 3. Soil moisture varied greatly in the upper soil layer and slowly in the deep soil layer. The CV under four pruning intensities changed from medium variability to low variability from the upper to the deep soil layer (Fig. 3e). Compared with the soil moisture in 2012, it infiltrated to the depths of 240, 220, 200 and $180 \mathrm{~cm}$ in 2013 under $\mathrm{C}_{3}, \mathrm{C}_{2}, \mathrm{C}_{1}$ and $\mathrm{CK}$ pruning intensities, respectively. Because rainfall in 2014 was lower than that in 2013, soil moisture was reduced in the upper soil layer, but the depths of soil moisture infiltration increased to $280,260,240$ and $200 \mathrm{~cm}$ under $\mathrm{C}_{3}, \mathrm{C}_{2}, \mathrm{C}_{1}$ and $\mathrm{CK}$ pruning intensities, respectively. This might be attributable to the hysteresis effect of soil moisture movement. In addition, in the dry year (2015), the depths of soil moisture infiltration increased under $\mathrm{C}_{3}$ and $\mathrm{C}_{2}$ pruning intensities ( $>300$ and $260 \mathrm{~cm}$, respectively) but decreased under $\mathrm{C}_{1}$ and $\mathrm{CK}$ pruning intensities (220 and $160 \mathrm{~cm}$, respectively). This suggests that greater pruning intensity is better for the dried soil layer recovery of the deep soil layer.

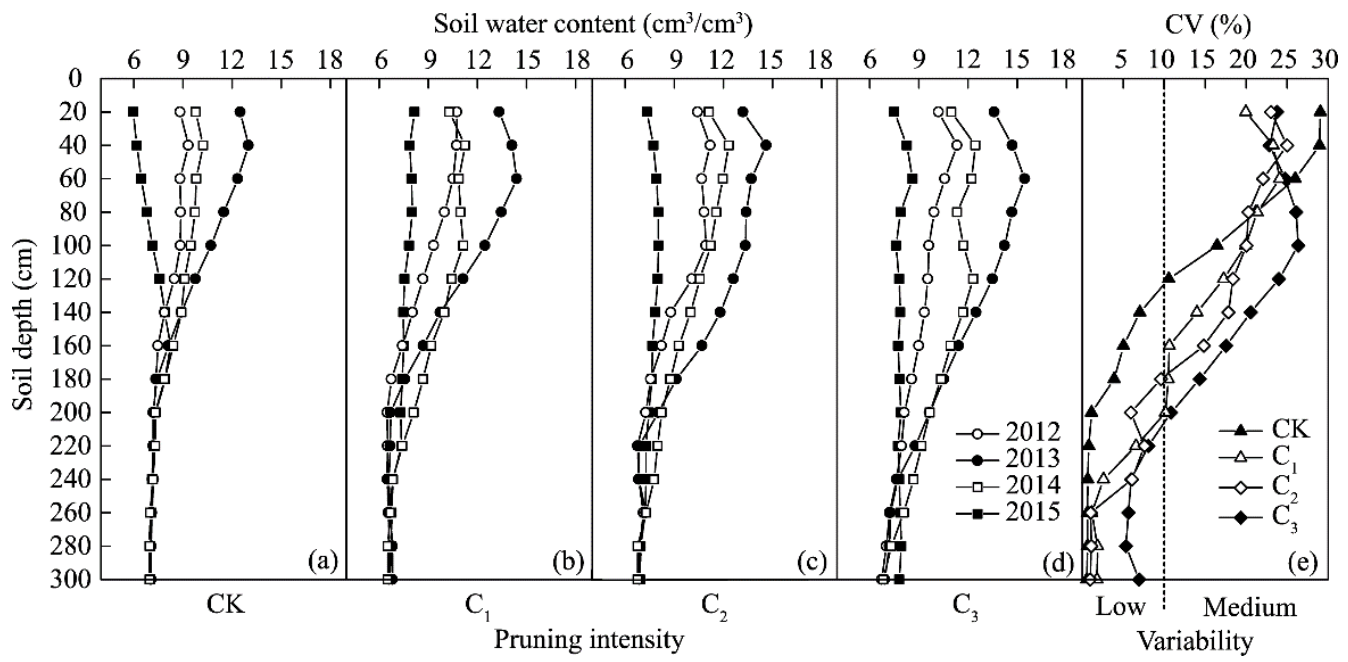

Fig. 3 Vertical distributions of soil water content in the 0-300 cm soil layer under (a) CK, (b) $C_{1}$, (c) $C_{2}$ and (d) $\mathrm{C}_{3}$ pruning intensities and (e) coefficient of variation $(\mathrm{CV})$ of soil water content during the jujube growing period of 2012-2015

\subsection{Soil water deficit}

Tables 3-6 list the degrees and statuses of soil water deficit under four pruning intensities during the jujube growing period of 2012-2015. Under CK pruning intensity, there was a moderate soil water deficit in the entire $0-300 \mathrm{~cm}$ soil layer in 2012, which then alleviated in the upper soil layer in 2013 due to heavy rainfall. Therefore, the decreased rainfall aggravated the soil water deficit. There was a moderate soil water deficit in the $0-300 \mathrm{~cm}$ soil layer (except that in the $20-40 \mathrm{~cm}$ soil layer) in 2014 and a serious soil water deficit in 2015 in the $0-60 \mathrm{~cm}$ soil layer. For 
other pruning intensities, different degrees of soil water deficit were observed over the four experimental years. In 2012, soil water deficit statuses under $C_{1}, C_{2}$ and $C_{3}$ pruning intensities were minor in the $0-80,0-120$ and $0-80 \mathrm{~cm}$ soil layers, respectively. In 2013 , there was no soil water deficit in the $0-60 \mathrm{~cm}$ soil layer under $C_{1}$ pruning intensity, 20-100 cm layer under $C_{2}$ pruning intensity and $0-120 \mathrm{~cm}$ layer under $C_{3}$ pruning intensity. However, in 2014, soil water deficit statuses were minor in the $0-140 \mathrm{~cm}$ soil layer under both $\mathrm{C}_{1}$ and $\mathrm{C}_{2}$ pruning intensities, and in the $0-180 \mathrm{~cm}$ soil layer under $\mathrm{C}_{3}$ pruning intensity. In 2015 , soil water deficit was moderate across all the soil layer under all pruning intensities.

Table 3 Status of soil water deficit under CK pruning intensity during the jujube growing period of 2012-2015

\begin{tabular}{|c|c|c|c|c|c|c|c|c|}
\hline \multirow{2}{*}{$\begin{array}{l}\text { Soil layer } \\
\quad(\mathrm{cm})\end{array}$} & \multicolumn{2}{|c|}{2012} & \multicolumn{2}{|c|}{2013} & \multicolumn{2}{|c|}{2014} & \multicolumn{2}{|c|}{2015} \\
\hline & $\begin{array}{c}\text { Deficit } \\
\text { degree }(\%)\end{array}$ & $\begin{array}{c}\text { Deficit } \\
\text { grade }\end{array}$ & $\begin{array}{c}\text { Deficit } \\
\text { degree (\%) }\end{array}$ & $\begin{array}{c}\text { Deficit } \\
\text { grade }\end{array}$ & $\begin{array}{c}\text { Deficit degree } \\
(\%)\end{array}$ & $\begin{array}{l}\text { Deficit } \\
\text { grade }\end{array}$ & $\begin{array}{c}\text { Deficit } \\
\text { degree }(\%)\end{array}$ & $\begin{array}{l}\text { Deficit } \\
\text { grade }\end{array}$ \\
\hline $0-20$ & 33.1 & Moderate & 5.3 & Minor & 25.8 & Moderate & 54.8 & Serious \\
\hline $20-40$ & 29.2 & Moderate & 1.5 & Minor & 22.5 & Minor & 53.1 & Serious \\
\hline $40-60$ & 33.1 & Moderate & 6.4 & Minor & 25.6 & Moderate & 51.0 & Serious \\
\hline $60-80$ & 32.8 & Moderate & 12.9 & Minor & 26.3 & Moderate & 48.5 & Moderate \\
\hline $80-100$ & 33.0 & Moderate & 18.8 & Minor & 28.1 & Moderate & 45.9 & Moderate \\
\hline $100-120$ & 35.7 & Moderate & 26.1 & Moderate & 31.0 & Moderate & 42.5 & Moderate \\
\hline $120-140$ & 40.3 & Moderate & 32.6 & Moderate & 32.4 & Moderate & 40.2 & Moderate \\
\hline $140-160$ & 43.3 & Moderate & 38.6 & Moderate & 36.3 & Moderate & 37.7 & Moderate \\
\hline $160-180$ & 44.3 & Moderate & 43.8 & Moderate & 40.2 & Moderate & 40.1 & Moderate \\
\hline $180-200$ & 45.4 & Moderate & 45.6 & Moderate & 44.5 & Moderate & 44.3 & Moderate \\
\hline $200-220$ & 45.5 & Moderate & 45.5 & Moderate & 44.6 & Moderate & 45.5 & Moderate \\
\hline $220-240$ & 45.3 & Moderate & 46.0 & Moderate & 45.7 & Moderate & 46.1 & Moderate \\
\hline $240-260$ & 46.2 & Moderate & 46.5 & Moderate & 47.0 & Moderate & 46.3 & Moderate \\
\hline $260-280$ & 46.5 & Moderate & 46.4 & Moderate & 47.2 & Moderate & 46.7 & Moderate \\
\hline $280-300$ & 46.5 & Moderate & 46.9 & Moderate & 47.2 & Moderate & 46.7 & Moderate \\
\hline
\end{tabular}

Table 4 Status of soil water deficit under $\mathrm{C}_{1}$ pruning intensity during the jujube growing period of 2012-2015

\begin{tabular}{|c|c|c|c|c|c|c|c|c|}
\hline \multirow{2}{*}{$\begin{array}{l}\text { Soil layer } \\
\quad(\mathrm{cm})\end{array}$} & \multicolumn{2}{|c|}{2012} & \multicolumn{2}{|c|}{2013} & \multicolumn{2}{|l|}{2014} & \multicolumn{2}{|c|}{2015} \\
\hline & $\begin{array}{c}\text { Deficit } \\
\text { degree }(\%)\end{array}$ & $\begin{array}{l}\text { Deficit } \\
\text { grade }\end{array}$ & $\begin{array}{c}\text { Deficit } \\
\text { degree (\%) }\end{array}$ & $\begin{array}{l}\text { Deficit } \\
\text { grade }\end{array}$ & $\begin{array}{c}\text { Deficit degree } \\
(\%)\end{array}$ & $\begin{array}{c}\text { Deficit } \\
\text { grade }\end{array}$ & $\begin{array}{c}\text { Deficit } \\
\text { degree }(\%)\end{array}$ & $\begin{array}{l}\text { Deficit } \\
\text { grade }\end{array}$ \\
\hline $0-20$ & 18.6 & Minor & -1.0 & None & 22.1 & Minor & 38.2 & Moderate \\
\hline $20-40$ & 18.7 & Minor & -7.0 & None & 14.8 & Minor & 40.4 & Moderate \\
\hline $40-60$ & 20.4 & Minor & -9.1 & None & 17.7 & Minor & 39.5 & Moderate \\
\hline $60-80$ & 24.2 & Minor & 2.0 & Minor & 17.0 & Minor & 39.3 & Moderate \\
\hline $80-100$ & 29.3 & Moderate & 5.6 & Minor & 15.6 & Minor & 40.7 & Moderate \\
\hline $100-120$ & 34.2 & Moderate & 15.6 & Minor & 21.0 & Minor & 42.8 & Moderate \\
\hline $120-140$ & 39.0 & Moderate & 26.3 & Moderate & 24.3 & Minor & 43.3 & Moderate \\
\hline $140-160$ & 43.7 & Moderate & 34.1 & Moderate & 30.5 & Moderate & 43.2 & Moderate \\
\hline $160-180$ & 48.9 & Moderate & 42.5 & Moderate & 34.2 & Moderate & 43.8 & Moderate \\
\hline $180-200$ & 49.2 & Moderate & 49.2 & Moderate & 38.5 & Moderate & 44.6 & Moderate \\
\hline $200-220$ & 49.2 & Moderate & 49.3 & Moderate & 43.9 & Moderate & 44.2 & Moderate \\
\hline $220-240$ & 49.2 & Moderate & 48.5 & Moderate & 48.2 & Moderate & 48.1 & Moderate \\
\hline $240-260$ & 48.7 & Moderate & 49.5 & Moderate & 49.4 & Moderate & 48.8 & Moderate \\
\hline $260-280$ & 49.7 & Moderate & 48.3 & Moderate & 49.0 & Moderate & 49.0 & Moderate \\
\hline $280-300$ & 49.7 & Moderate & 48.3 & Moderate & 49.0 & Moderate & 49.5 & Moderate \\
\hline
\end{tabular}


Table 5 Status of soil water deficit under $\mathrm{C}_{2}$ pruning intensity during the jujube growing period of 2012-2015

\begin{tabular}{|c|c|c|c|c|c|c|c|c|}
\hline \multirow{2}{*}{$\begin{array}{l}\text { Soil layer } \\
\quad(\mathrm{cm})\end{array}$} & \multicolumn{2}{|c|}{2012} & \multicolumn{2}{|c|}{2013} & \multicolumn{2}{|c|}{2014} & \multicolumn{2}{|c|}{2015} \\
\hline & $\begin{array}{c}\text { Deficit } \\
\text { degree }(\%)\end{array}$ & $\begin{array}{l}\text { Deficit } \\
\text { grade }\end{array}$ & $\begin{array}{c}\text { Deficit } \\
\text { degree }(\%)\end{array}$ & $\begin{array}{l}\text { Deficit } \\
\text { grade }\end{array}$ & $\begin{array}{c}\text { Deficit degree } \\
(\%)\end{array}$ & $\begin{array}{l}\text { Deficit } \\
\text { grade }\end{array}$ & $\begin{array}{c}\text { Deficit } \\
\text { degree }(\%)\end{array}$ & $\begin{array}{c}\text { Deficit } \\
\text { grade }\end{array}$ \\
\hline $0-20$ & 20.9 & Minor & 0.1 & Minor & 15.8 & Minor & 44.4 & Moderate \\
\hline $20-40$ & 15.2 & Minor & -10.7 & None & 6.5 & Minor & 41.4 & Moderate \\
\hline $40-60$ & 19.1 & Minor & -3.9 & None & 9.3 & Minor & 40.0 & Moderate \\
\hline $60-80$ & 17.9 & Minor & -1.5 & None & 12.3 & Minor & 39.1 & Moderate \\
\hline $80-100$ & 17.2 & Minor & -1.1 & None & 14.9 & Minor & 39.1 & Moderate \\
\hline $100-120$ & 23.6 & Minor & 4.4 & Minor & 20.0 & Minor & 39.4 & Moderate \\
\hline $120-140$ & 33.3 & Moderate & 10.5 & Minor & 24.3 & Minor & 40.7 & Moderate \\
\hline $140-160$ & 37.6 & Moderate & 18.9 & Minor & 29.6 & Moderate & 41.9 & Moderate \\
\hline $160-180$ & 42.7 & Moderate & 30.8 & Moderate & 33.6 & Moderate & 42.2 & Moderate \\
\hline $180-200$ & 44.9 & Moderate & 39.2 & Moderate & 37.6 & Moderate & 43.6 & Moderate \\
\hline $200-220$ & 48.7 & Moderate & 48.0 & Moderate & 39.5 & Moderate & 44.8 & Moderate \\
\hline $220-240$ & 48.2 & Moderate & 48.1 & Moderate & 41.2 & Moderate & 44.8 & Moderate \\
\hline $240-260$ & 46.1 & Moderate & 45.0 & Moderate & 44.8 & Moderate & 45.2 & Moderate \\
\hline $260-280$ & 47.7 & Moderate & 47.8 & Moderate & 48.7 & Moderate & 47.3 & Moderate \\
\hline $280-300$ & 47.7 & Moderate & 47.8 & Moderate & 48.7 & Moderate & 47.7 & Moderate \\
\hline
\end{tabular}

Table 6 Status of soil water deficit under $C_{3}$ pruning intensity during the jujube growing period of 2012-2015

\begin{tabular}{|c|c|c|c|c|c|c|c|c|}
\hline \multirow{2}{*}{$\begin{array}{l}\text { Soil layer } \\
\quad(\mathrm{cm})\end{array}$} & \multicolumn{2}{|c|}{2012} & \multicolumn{2}{|c|}{2013} & \multicolumn{2}{|c|}{2014} & \multicolumn{2}{|c|}{2015} \\
\hline & $\begin{array}{c}\text { Deficit } \\
\text { degree }(\%)\end{array}$ & $\begin{array}{l}\text { Deficit } \\
\text { grade }\end{array}$ & $\begin{array}{c}\text { Deficit } \\
\text { degree (\%) }\end{array}$ & $\begin{array}{l}\text { Deficit } \\
\text { grade }\end{array}$ & $\begin{array}{c}\text { Deficit degree } \\
(\%)\end{array}$ & $\begin{array}{l}\text { Deficit } \\
\text { grade }\end{array}$ & $\begin{array}{c}\text { Deficit } \\
\text { degree }(\%)\end{array}$ & $\begin{array}{l}\text { Deficit } \\
\text { grade }\end{array}$ \\
\hline $0-20$ & 22.7 & Minor & -3.1 & None & 16.8 & Minor & 43.2 & Moderate \\
\hline $20-40$ & 14.1 & Minor & -11.3 & None & 5.7 & Minor & 37.4 & Moderate \\
\hline $40-60$ & 19.9 & Minor & -17.2 & None & 7.4 & Minor & 34.8 & Moderate \\
\hline $60-80$ & 24.8 & Minor & -11.3 & None & 14.1 & Minor & 40.3 & Moderate \\
\hline $80-100$ & 27.1 & Moderate & -7.8 & None & 11.3 & Minor & 42.5 & Moderate \\
\hline $100-120$ & 27.6 & Moderate & -2.3 & None & 6.7 & Minor & 40.9 & Moderate \\
\hline $120-140$ & 29.1 & Moderate & 5.3 & Minor & 11.4 & Minor & 40.4 & Moderate \\
\hline $140-160$ & 31.8 & Moderate & 13.3 & Minor & 17.2 & Minor & 41.4 & Moderate \\
\hline $160-180$ & 35.1 & Moderate & 20.2 & Minor & 21.6 & Minor & 40.8 & Moderate \\
\hline $180-200$ & 38.5 & Moderate & 26.9 & Moderate & 26.8 & Moderate & 40.1 & Moderate \\
\hline $200-220$ & 39.7 & Moderate & 33.4 & Moderate & 30.6 & Moderate & 41.5 & Moderate \\
\hline $220-240$ & 42.1 & Moderate & 41.5 & Moderate & 34.4 & Moderate & 40.9 & Moderate \\
\hline $240-260$ & 45.3 & Moderate & 44.9 & Moderate & 38.8 & Moderate & 40.3 & Moderate \\
\hline $260-280$ & 46.9 & Moderate & 45.5 & Moderate & 44.5 & Moderate & 40.0 & Moderate \\
\hline $280-300$ & 48.9 & Moderate & 47.6 & Moderate & 48.3 & Moderate & 40.9 & Moderate \\
\hline
\end{tabular}

\subsection{Soil water balance}

Changes in soil water storage under four pruning intensities in each soil layer were calculated in 2013, 2014 and 2015 (Fig. 4). Positive value indicated a soil moisture surplus, while negative value denoted a deficit. There were large differences in the vertical distribution of changes in soil water storage in the three years. In 2013, soil moisture recharged in the $0-300 \mathrm{~cm}$ soil layer under four pruning intensities (Fig. 4a). In 2014, soil water deficit was observed in the upper layer under $\mathrm{CK}, \mathrm{C}_{1}$ and $\mathrm{C}_{2}$ pruning intensities (Fig. 4b). However, in 2015, changes in soil water storage under all pruning intensities were negative (Fig. 4c). Figure 4 also shows that in any 
hydrological year, greater pruning intensity would result in greater soil moisture supply and less soil water deficit. From 2013 to 2015, changes in soil water storage in the $0-300 \mathrm{~cm}$ soil layer under $\mathrm{CK}, \mathrm{C}_{1}, \mathrm{C}_{2}$ and $\mathrm{C}_{3}$ pruning intensities were $-40.6,-20.5,6.4$ and $26.8 \mathrm{~mm}$, respectively.

\subsection{Effects of pruning intensity on fresh biomass of jujube}

Figure 5 shows the fresh biomass of each jujube organ at the fruit ripening stage under four

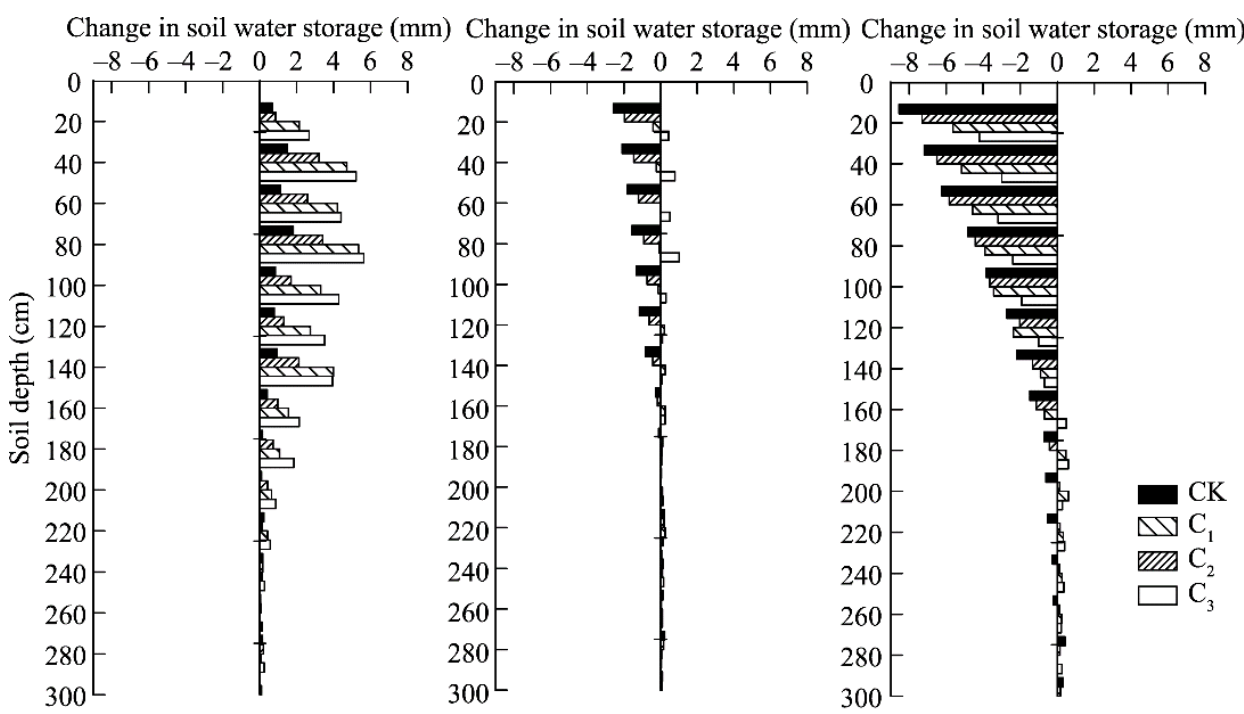

(a) 2013

(b) 2014

(c) 2015

Fig. 4 Changes in soil water storage under $C K, C_{1}, C_{2}$ and $C_{3}$ pruning intensities in (a) 2013 (wet year), (b) 2014 (wet year) and (c) 2015 (dry year)
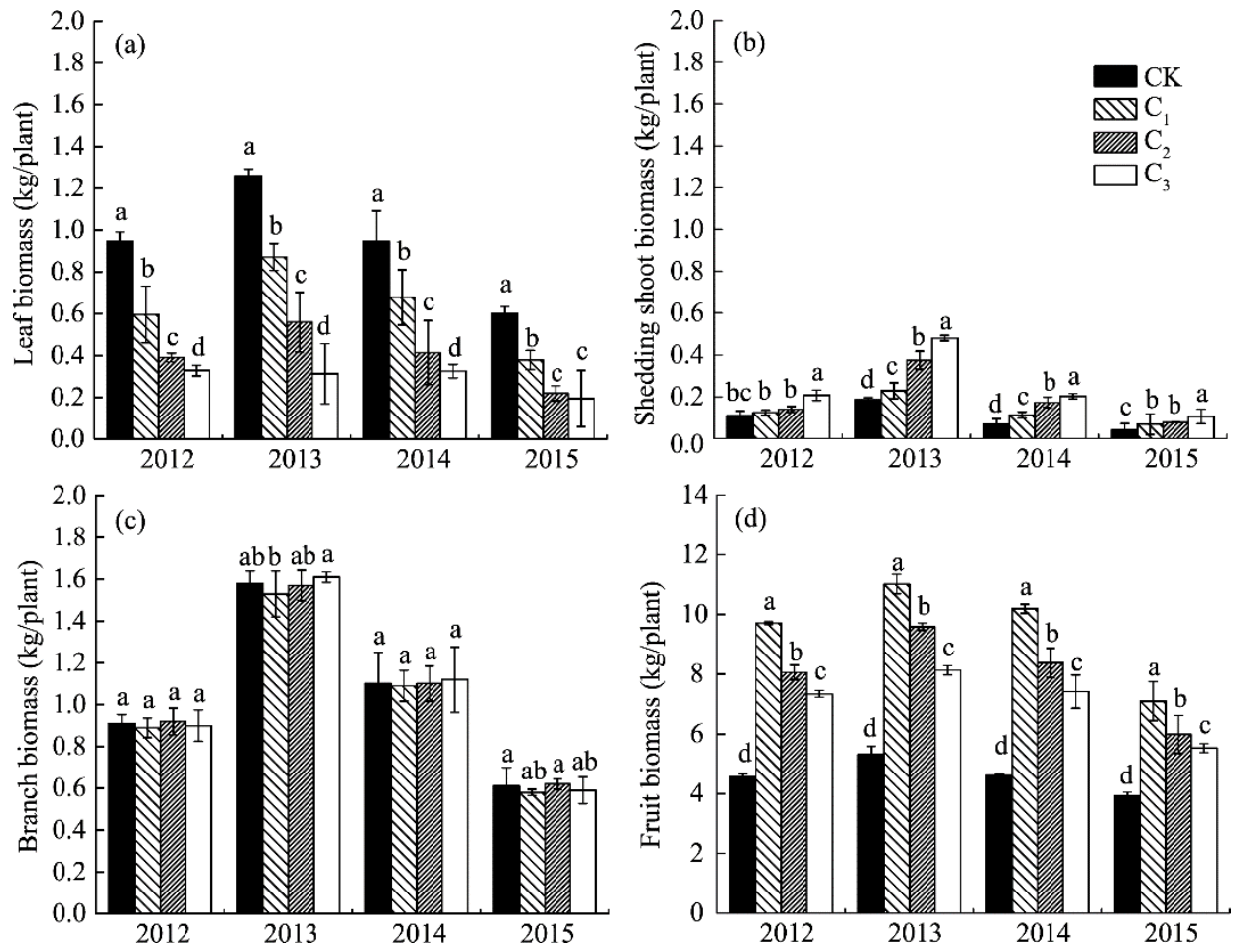

Fig. 5 Fresh biomass in (a) leaves, (b) shed shoots, (c) branches and (d) fruits of jujube plants under $\mathrm{CK}_{1} \mathrm{C}_{1}, \mathrm{C}_{2}$ and $\mathrm{C}_{3}$ pruning intensities at the fruit ripening stage during the growing period of 2012-2015. Different lowercase letters within the same year represent significant differences among four pruning intensities at $P<0.05$ level according to LSD multiple tests. Bar means the standard deviation. 
pruning intensities. Jujube plants had the highest leaf biomass under $\mathrm{CK}$ pruning intensity, which was significantly higher than those under $C_{1}, C_{2}$ and $C_{3}$ pruning intensities $(P<0.05$; Fig. 5a). Leaf biomass was negatively related to pruning intensity. However, shed shoot biomass increased with increasing pruning intensity (Fig. 5b). There were significant differences in shed shoot biomass between $\mathrm{C}_{3}$ and all other pruning intensities $(P<0.05)$ in all years. The highest fruit biomass was found under $\mathrm{C}_{1}$ pruning intensity and the lowest under $\mathrm{CK}$ pruning intensity (Fig. 5d). Furthermore, no significant differences in branch biomass (including the pruned branches) were observed among any of the pruning intensities $(P<0.05$; Fig. $5 \mathrm{c})$. Moreover, the biomass of each organ was highest in the wet year (2013) and lowest in the dry year (2015), indicating that rainfall is a decisive factor in jujube growth.

\subsection{Effects of pruning intensity on water use efficiency (WUE)}

Water consumption, fruit yield and WUE under four pruning intensities during the jujube growing period of 2012-2015 are shown in Figure 6. Soil water consumption was highest under CK pruning intensity and it was reduced with increasing pruning intensity, which suggested that greater pruning intensity resulted in better soil water conservation. Pruning significantly improved fresh fruit yield and WUE of jujube plants. Fresh fruit yields were highest under $\mathrm{C}_{1}$ pruning intensity with the values of $6897.1-13,059.3 \mathrm{~kg} / \mathrm{hm}^{2}$, which were $2758.4-4712.8$, 385.7-1432.1 and 802.8-2331.5 kg/hm ${ }^{2}$ higher than those under $\mathrm{CK}, \mathrm{C}_{2}$ and $\mathrm{C}_{3}$ pruning intensities in 2012-2015, respectively. However, $C_{3}$ pruning intensity had the highest WUE values $\left(2.92-3.13 \mathrm{~kg} / \mathrm{m}^{3}\right)$, which were 1.6-2.0, 1.1-1.2 and 1.0-1.1 times greater than those under $\mathrm{CK}, \mathrm{C}_{1}$ and $\mathrm{C}_{2}$ pruning intensities, respectively. Fruit yield varied among different years. Although fruit yield in 2015 was approximately half of that in 2013, WUE was highest in this year, which highlighted the potential contribution of pruning to water-limited areas.
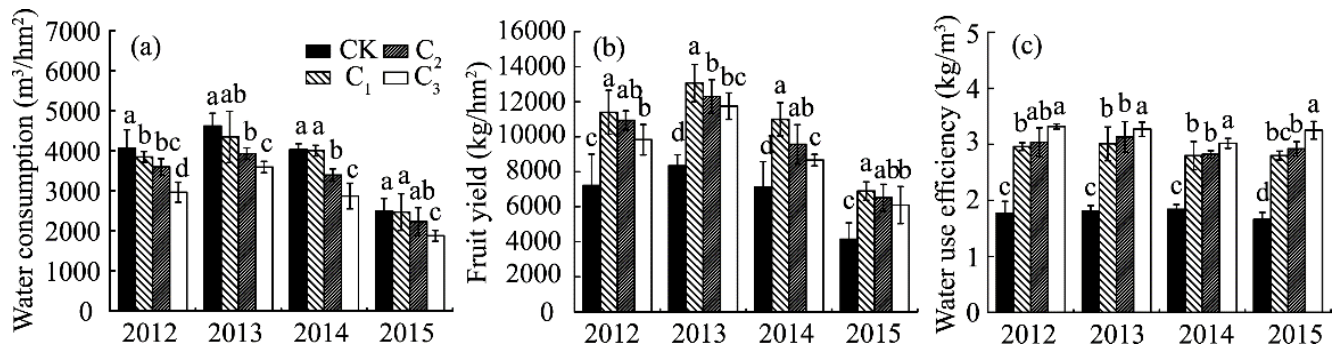

Fig. 6 Water consumption (a), fruit yield (b) and water use efficiency (c) under four pruning intensities during the jujube growing period of 2012-2015. Different lowercase letters within the same year represent significant differences among four pruning intensities at $P<0.05$ level according to LSD multiple tests. Bar means the standard deviation.

\section{Discussion}

Previous studies showed that 0-200 $\mathrm{cm}$ soil depth was the main layer of rainfall infiltration and plant root distribution in the hilly Loess Plateau Region (Liu et al., 2013; Wang et al., 2015). Thus, soil moisture in this depth has been usually considered in relevant studies. For jujube trees, Ma et al. (2012) showed that root intersects of one-year-old tree were concentrated in 0-40 cm soil layer, and four-year-old, eight-year-old and eleven-year-old tree root intersects were mainly in 0-60 $\mathrm{cm}$ soil layer. However, Liu et al. (2014) found that root growth extended to the deep soil layer $(>200 \mathrm{~cm})$ to absorb more water as jujube water requirements were not met by rainfall or drip irrigation. Wang et al. (2017) showed that the depth of soil moisture infiltration reached 460 $\mathrm{cm}$ after cutting jujube tree trunks for three consecutive years. In our study, the depth of soil moisture was $>300 \mathrm{~cm}$ under $\mathrm{C}_{3}$ pruning intensity. These results indicated that the commonly used soil depth is suitable for test needs. However, a greater depth $(>500 \mathrm{~cm})$ should be considered for future research on soil ecology. In addition, in our experimental design, only 100 $\mathrm{cm}$ depth was excavated to avoid lateral soil water input to the sample trees, which was insufficient and should be expanded in future studies. 
Stand transpiration accounted for over half of the total water consumption (Chen et al., 2016), thus, management measures are necessary to suppress plant transpiration and prevent soil desiccation. Pruning can be an effective way to reduce tree water use by changing the canopy architecture and reducing canopy leaf area, leading to an improvement in the soil water replenishment rate (Shelden and Sinclair, 2000; López et al., 2008; Hipps et al., 2014; Afonso et al., 2017). However, pruning of tree canopies should be at an appropriate intensity, or it may be more effectively coupled to the atmosphere, as it increases rather than decreases transpiration (Jarvis and Mcnaughton, 1986; Wullschleger et al., 2000). Jackson et al. (2000) found that only severe pruning of tree canopies reduced the water requirements of trees. Hipps et al. (2014) also argued that canopy thinning (removal of $30 \%$ of the lateral branches) had no effect on limiting water demand, whereas canopy reduction (removal of the outer $30 \%$ of all major branches) conserved soil moisture for up to three years. A similar phenomenon was observed in our study, that is, soil water storage increased under three pruning intensities $\left(\mathrm{C}_{1}, \mathrm{C}_{2}\right.$ and $\left.\mathrm{C}_{3}\right)$ compared to $\mathrm{CK}$ pruning intensity, and high $\left(\mathrm{C}_{3}\right)$ pruning intensity had better water conservation effects.

Although previous studies indicated that pruning of branches was indeed beneficial to the recovery of dried soil layer, there was no clear indication of the exact depth or degree of its recovery (Wei et al., 2014; Chen et al., 2016; Nie et al., 2017). In the present study, minor or moderate soil water deficit was observed under four pruning intensities. In addition, soil desiccation was somewhat alleviated with increasing pruning intensity. However, the recovery of dried soil layer mainly occurred in the upper soil layer, even under the high pruning intensity. This might be attributable to the extreme drought condition. We also found that the depth of soil moisture infiltration was enhanced and reached up to $>300 \mathrm{~cm}$ under $\mathrm{C}_{3}$ pruning intensity, indicating that pruning promotes the replenishment of deep soil moisture and the recovery of dried soil layer.

Leaf biomass was significantly lower under $\mathrm{C}_{1}, \mathrm{C}_{2}$ and $\mathrm{C}_{3}$ pruning intensities compared to $\mathrm{CK}$ pruning intensity, while shed shoot biomass and fruit biomass were higher, leading to a higher fruit yield. This finding indicates that pruning improves the proportions of vegetative and generative plant parts (Ambroszczyk et al., 2007). Many researchers have found that pruning can improve fruit yield and quality by enabling greater access to light, water and nutrients (Reynolds, 1989; Seifi et al., 2011; Bhagawati et al., 2015). However, we also observed a non-linear relationship between pruning intensity and fruit yield. Jujube plants under $\mathrm{C}_{1}$ pruning intensity had the highest yield, so pruning within a limited range of intensity had a positive effect. Jorquerafontena et al. (2014) found that yield and berries per plant decreased with increasing pruning intensity.

Pruning intensity increased the WUE partly because it markedly reduced the soil water consumption. Previous researchers proposed a conceptual "water-saving pruning measure" to control soil desiccation in jujube plantations (Zhao et al., 2012). According to this strategy, soil water content determines the fruit yield and fruit yield determines the tree size. Similarly, our results further implied that local average annual rainfall, soil moisture status and the physiological characteristics of jujube plants determine the yield and then the appropriate yield determines the canopy structure of tree. Zhao et al. (2012) showed that a sustainable water-saving pruning strategy is not only based on the maximum yield, but also should avoid excessive use of soil moisture for sustainable management of plantations. In the present study, compared with $\mathrm{C}_{2}$ and $\mathrm{C}_{3}$, although $\mathrm{C}_{1}$ pruning intensity produced the highest yield, it had the lowest WUE. Furthermore, $\mathrm{C}_{3}$ pruning intensity produced the highest WUE and also an acceptable yield. Therefore, in the range of pruning intensities tested, $\mathrm{C}_{3}$ pruning intensity is recommended for its economic and ecological benefits. However, in order to obtain the optimal pruning intensity to improve yield and WUE, more pruning intensity gradients should be considered in future experiments.

\section{Conclusions}

Pruning is an effective way for conserving water resources in jujube plantations in the hilly Loess 
Plateau Region. Soil water storage significantly increased during the jujube growing period of 2012-2015 under $C_{1}, C_{2}$ and $C_{3}$ pruning intensities, compared to $C K$ pruning intensity. Pruning promoted soil moisture migration to the deep soil layer and improved the recovery of dried soil layer. Soil water change was positive both under $\mathrm{C}_{2}$ and $\mathrm{C}_{3}$ pruning intensities and negative under $\mathrm{C}_{1}$ and $\mathrm{CK}$ pruning intensities in 2013-2015. Pruning promoted the reproductive growth (shed shoots biomass and fruit biomass) and inhibited the vegetative growth (leaf biomass), resulting in a high yield and WUE. The $\mathrm{C}_{3}$ pruning intensity is recommended for its economic of jujube plants and ecological benefits.

\section{Acknowledgements}

This work was supported by the China National Support Program (2015BAC01B03), the Shaanxi Co-ordination Program (2016KTZDNY0105) and the National Key Research and Development Program of China (2016YED0300201). The authors would like to thank the staff of Mizhi Experimental Station of Northwest A\&F University and the anonymous reviewers for their valuable contributions.

\section{References}

Afonso S, Ribeiro C, Bacelar E, et al. 2017. Influence of training system on physiological performance, biochemical composition and antioxidant parameters in apple tree (Malus domestica Borkh.). Scientia Horticulturae, 225: 394-398.

Alcorn P J, Forrester D I, Thomas D S, et al. 2013. Changes in whole-tree water use following live-crown pruning in young plantation-grown Eucalyptus pilularis and Eucalyptus cloeziana. Forests, 4(1): 106-121.

Ambroszczyk A M, Cebula S, Sekara A. 2007. The effect of plant pruning on yield and fruit quality of eggplant (Solanum melongena L.) in greenhouse cultivation. Horticulture Environment and Biotechnology, 48(5): 277-285.

Bhagawati R, Bhagawati K, Choudhary V K, et al. 2015. Effect of pruning intensities on the performance of fruit plants under mid-hill condition of eastern Himalayas: case study on guava. International Letters of Natural Sciences, 46: 46-51.

Chen D Y, Wang Y K, Wang X, et al. 2016. Effects of branch removal on water use of rain-fed jujube (Ziziphus jujuba Mill.) plantations in Chinese semiarid Loess Plateau region. Agricultural Water Management, 178: 258-270.

Chen H S, Wang K L, Shao M A. 2005. A review on the effect of vegetation rehabilitation on the desiccation of deep soil layer on the Loess Plateau. Scientia Silvae Sinicae, 41(4): 155-161. (in Chinese)

Chen H S, Shao M A, Li Y Y. 2008. Soil desiccation in the Loess Plateau of China. Geoderma, 143(1-2): 91-100.

Fan J, Yu G, Wang Q, et al. 2014. Mulching effects on water storage in soil and its depletion by alfalfa in the Loess Plateau of northwestern China. Agricultural Water Management, 138: 10-16.

Fang X Y, Li J, Wang X C, et al. 2010. Soil desiccation of alfalfa fields and effects of alfalfa-grain crop rotation on soil water restoration of desiccated alfalfa fields in semi-humid areas of the Loess Plateau. Scientia Agricultura Sinica, 43(16): 3348-3356. (in Chinese)

Forrester D I, Collopy J J, Beadle C L, et al. 2012. Effect of thinning, pruning and nitrogen fertiliser application on transpiration, photosynthesis and water-use efficiency in a young Eucalyptus nitens plantation. Forest Ecology and Management, 266(288): 286-300.

Fu W, Huang M B, Gallichand J, et al. 2012. Optimization of plant coverage in relation to water balance in the Loess Plateau of China. Geoderma, 173: 134-144.

Gao X D, Li H C, Zhao X N, et al. 2018. Identifying a suitable revegetation technique for soil restoration on water-limited and degraded land: considering both deep soil moisture deficit and soil organic carbon sequestration. Geoderma, 319: 61-69.

Hipps N A, Davies M J, Dunn J M, et al. 2014. Effects of two contrasting canopy manipulations on growth and water use of London plane (Platanus $\times$ acerifolia) trees. Plant and Soil, 382(1-2): 61-74.

Hussain G, Al-Jaloud A A. 1998. Effect of irrigation and nitrogen on yield, yield components and water use efficiency of barley in Saudi Arabia. Agricultural Water Management, 36(1): 55-70.

Jackson N A, Wallace J S, Ong C K. 2000. Tree pruning as a means of controlling water use in an agroforestry system in Kenya. Forest Ecology and Management, 126(2): 133-148.

Jarvis P G, McNaughton K. 1986. Stomatal control of transpiration: scaling up from leaf to region. Advances in Ecological Research, 15(15): 1-49. 
Jia X X, Shao M A, Zhu Y J, et al. 2017. Soil moisture decline due to afforestation across the Loess Plateau, China. Journal of Hydrology, 546: 113-122.

Jipp P H, Nepstad D C, Cassel D K, et al. 1998. Deep soil moisture storage and transpiration in forests and pastures of seasonally-dry amazonia. Climatic Change, 39(2-3): 395-412.

Jorquerafontena E, Alberdi M, Franck N. 2014. Pruning severity affects yield, fruit load and fruit and leaf traits of 'Brigitta' blueberry. Journal of Soil Science and Plant Nutrition, 14(4): 855-868.

Li Y S. 1983. The properties of water cycle in soil and their effect on water cycle for land in the Loess Region. Acta Ecologica Sinica, 3(2): 91-101. (in Chinese)

Liu X L, Wang Y K, Ma L F, et al. 2013. Relationship between deep soil water vertical variation and root distribution in dense jujube plantation. Transactions of the Chinese Society for Agricultural Machinery, 44(7): 90-97, 106. (in Chinese)

Liu X L, Ma L H, Yang R H, et al. 2014. Deep soil water depletion characteristic of jujube plantation in Loess semiarid region. Transactions of the Chinese Society for Agricultural Machinery, 45(12): 139-145. (in Chinese)

López G, Arbones A, del Campo J, et al. 2008. Response of peach trees to regulated deficit irrigation during stage II of fruit development and summer pruning. Spanish Journal of Agricultural Research, 6(3): 479-491.

Ma L H, Wu P T, Wang Y K. 2012. Spatial pattern of root systems of dense jujube plantation with jujube age in the semiarid loess hilly region of China. Chinese Journal of Plant Ecology, 36(4): 292-301. (in Chinese)

Martin L W, Nelson E, Chaplin M H. 1980. Plant and fruit measurements of 'Meeker' red raspberry related to pruning height and nitrogen application. Acta Horticulturae, 112: 157-162.

Max J F J, Schmidt L, Mutwiwa U N, et al. 2016. Effects of shoot pruning and inflorescence thinning on plant growth, yield and fruit quality of greenhouse tomatoes in a tropical climate. Journal of Agriculture and Rural Development in the Tropics and Subtropics, 117(1): 45-56.

Namirembe S, Brook R M, Ong C K. 2009. Manipulating phenology and water relations in senna spectabilis in a water limited environment in Kenya. Agroforestry Systems, 75(3): 197-210.

Nie Z Y, Wang X, Wang Y K, et al. 2017. Effects of pruning intensity on jujube transpiration and soil moisture of plantation in the Loess Plateau. IOP Conference Series: Earth and Environmental Science, 52: 012048.

Oliveira R S, Bezerra L, Davidson E A, et al. 2005. Deep root function in soil water dynamics in cerrado savannas of central Brazil. Functional Ecology, 19(4): 574-581.

Pei J B, Chang X J, Li Y D, et al. 2013. Effect of pruning perennial main canes on fruit yield and quality of blueberry cuttivar 'Northland'. Shandong Agricultural Sciences, 45(1): 60-62, 66. (in Chinese)

Reynolds A G. 1989. Impact of pruning strategy, cluster thinning, and shoot removal on growth, yield, and fruit composition of low-vigor De Chaunac vines. Canadian Journal of Plant Science, 69(1): 269-275.

Robinson N, Harper R J, Smettem K R J. 2006. Soil water depletion by Eucalyptus spp. integrated into dryland agricultural systems. Plant and Soil, 286(1-2): 141-151.

Seifi S, Nemati S H, Shoor M, et al. 2011. Effect of plant density and shoot pruning on fruit quality characteristics of two cultivars of sweet pepper. Journal of Science \& Technology of Greenhouse Culture, 3(11): 77-83.

Shangguan Z P. 2007. Soil desiccation occurrence and its impact on forest vegetation in the Loess Plateau of China. International Journal of Sustainable Development \& World Ecology, 14(3): 299-306.

Shao M A, Jia X X, Wang Y Q, et al. 2016. A review of studies on dried soil layers in the Loess Plateau. Advances in Earth Science, 31(1): 14-22. (in Chinese)

She T, Wang Y K, Gao Z Y, et al. 2015. Biomass models for jujube in loess hilly mountain of northern Shanxi Province. Bulletin of Soil and Water Conservation, 35(3): 311-316. (in Chinese)

Shelden M, Sinclair R. 2000. Water relations of feral olive trees (Olea europaea) resprouting after severe pruning. Australian Journal of Botany, 48(5): 639-644.

Wang C L, Peng L Z, Cao L, et al. 2012. Effect of pruning methods on yield and quality of citrus and its economic benefits analysis. Journal of Fruit Science, 29(6): 1017-1021. (in Chinese)

Wang L, Shao M A. 2004. Soil desiccation under the returning farms to forests on the Loess Plateau. World Forestry Research, 17(4): 57-60. (in Chinese)

Wang X, Zhou Y H, Wang Y K, et al. 2015. Soil water characteristic of a dense jujube plantation in the semi-arid hilly regions of the Loess Plateau in China. Journal of Hydraulic Engineering, 46(3): 263-270. (in Chinese) 
Wang X, Gao Z Y, Gao J E, et al. 2017. The relationships between tree crown size and water consumption of rain-fed jujube plantation in Loess Hilly region. Transactions of the Chines Society for Agricultural Machinery, 48(5): 227-236. (in Chinese)

Wang X L, Sun G J, Jia Y, et al. 2008. Crop yield and soil water restoration on 9-year-old alfalfa pasture in the semiarid Loess Plateau of China. Agricultural Water Management, 95(3): 190-198.

Wang Y K, Hui Q, Wang X, et al. 2017. Growth and water use efficiency of water-saving type pruning jujube tree in dry soil. Transactions of the Chinese Society for Agricultural Machinery, 48(2): 247-254. (in Chinese)

Wei X G, Chen D Y, Liu S Y, et al. 2014. Effect of trim on jujube transpiration in Loess Hilly region. Transactions of the Chinese Society for Agricultural Machinery, 45(12): 194-202. (in Chinese)

Wullschleger S D, Wilson K B, Hanson P J. 2000. Environmental control of whole-plant transpiration, canopy conductance and estimates of the decoupling coefficient for large red maple trees. Agricultural and Forest Meteorology, 104(2): 157-168.

Xin X G, Wu P T, Wang Y K, et al. 2012. Study on soil water condition of mountain jujube yards of different growth years. Agricultural Research in the Arid Areas, 30(3): 85-89. (in Chinese)

Yang W Z, Han S F. 1985. Soil water ecological environment on the man-made woodland and grassland in loess hilly region. Journal of Soil and Water Conservation Research, 2: 18-28. (in Chinese)

Yang Z, Zhou Y, Fu Y, et al. 1998. Relationship between microclimatic character of different crown types and fruit quality of Fuji apple. Chinese Journal of Applied Ecology, 9: 533-537. (in Chinese)

Yi L, Li K R, Zhang G H, et al. 2009. Soil moisture deficit in artificial forest land in Loess Plateau. Journal of Northwest Forestry University, 24(5): 5-9. (in Chinese)

Zhang B Y, Xu X X, Liu W Z, et al. 2008. Dynamic changes of soil moisture in loess hilly and gully region under effects of different yearly precipitation patterns. Chinese Journal of Applied Ecology, 19(6): 1234-1240. (in Chinese)

Zhang C C, Shao M A, Wang Y Q, et al. 2016. Effects of gullies on the spatiotemporal variability of soil-water under different vegetation types on the Loess Plateau. Advances in Water Science, 27(5): 679-686. (in Chinese)

Zhang W F, Wang X, Wang Y K, et al. 2017. Growth and water consumption of jujube with water-saving pruning in deep dried soil of Loess Hilly Area. Transactions of the Chinese Society for Agricultual Engineering, 33(7): 140-148. (in Chinese)

Zhao X, Wang Y K, Liu S Y, et al. 2012. Effects of two new dryland farming technologies on growth and fruit bearing of pear jujube trees in hilly regions. Agricultural Research in the Arid Areas, 30(4): 157-160, 171. (in Chinese)

Zhao X. 2013. Pruning effects on sap flow and transporation assignment of photosynthates in grapevine. MSc Thesis. Yangling: Northwest A\&F University: 13-24. (in Chinese) 